1)

\title{
Specific Features of Wendelstein 7-X Structural Analyses
}

\author{
Victor Bykov, Joris Fellinger, Felix Schauer, Matthias Köppen, Konstantin Egorov, \\ Paul van Eeten, Andzej Dudek, and Tamara Andreeva
}

\begin{abstract}
The Wendelstein 7-X modular stellarator is in the final assembly phase at the Max Planck Institute for Plasma Physics in Greifswald, Germany. The design and assembly of the basic machine, that is, without in-vessel components, diagnostics and periphery, is completed. Structural parameters such as bolt preload, initial gap widths for contacts between structure elements, final magnet module positions, etc., were specified on the basis of detail numerical modeling and are now implemented. The focus of the numerical analysis has been shifted toward fast consideration of nonconformities and changes in assembly procedures, to preparation of commissioning, assessment of possible field disturbances, and exploration of operational limits. In parallel the analyses of in-vessel components, diagnostics, and periphery are being continued. This paper focuses on the specific features in the development, evolution, and realization of analysis strategies, implemented numerical approaches. Further specific subjects are standards and codes, safety margins in relation to expected tolerances and uncertainties, and the confirmation of analysis results by tests as well as their benchmarking with alternative models in different numerical codes. Finally, some lessons learned so far which might be relevant for other large fusion machines are highlighted, and a brief outlook on future work is given.
\end{abstract}

Index Terms - Analyses, construction, modeling, stellarator, Wendelstein 7-X (W7-X).

\section{INTRODUCTION}

W

ENDELSTEIN 7-X (W7-X), the largest optimized stellarator in the world, is in advanced stage of assembly at the Max Planck Institute for Plasma Physics in Greifswald, Germany. The design and assembly of the basic machine, that is, without in-vessel components, diagnostics and periphery, is completed as shown in Fig. 1. The project team goal is to start the technical commissioning in spring 2014 and plasma operation one year later [1], [2]. The main structural components of W7-X are presented schematically in Fig. 2 and on the photo from the status of the machine in the end of 2010 in Fig. 3. Both the optimized plasma shape and corresponding magnetic field are the basis for the configuration and design of the plasma vessel (PV) and the magnet system (MS). The W7-X magnet system consists

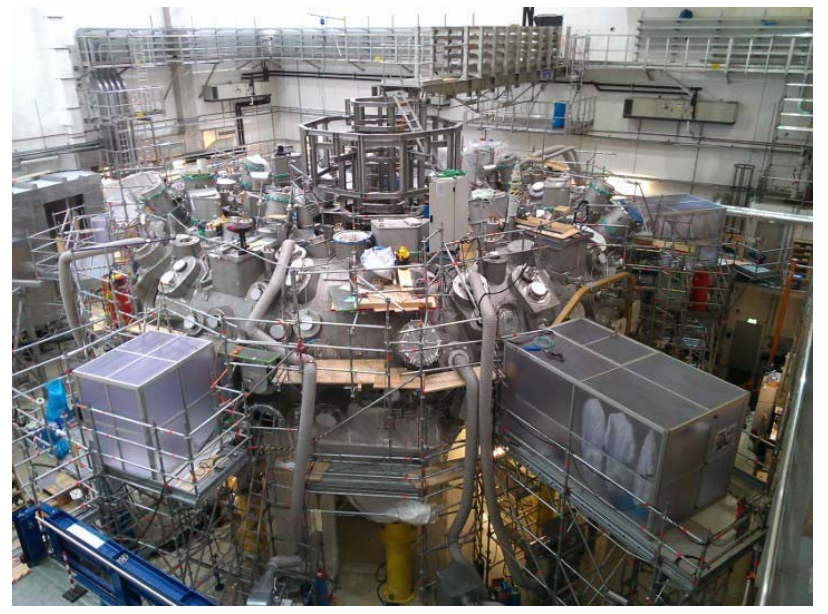

Fig. 1. W7-X assembly status in August 2013.

of 50 superconducting nonplanar coils (NPC), 20 superconducting planar coils (PLC), and the sophisticated mechanical structure encompassing the central support structure (CSS) and the intercoil support structure. The CSS stands on the machine base (MB) by 10 cryolegs. The NPCs have a complex 3-D geometry to ensure the required magnet field configuration with high precision.

The coils are arranged toroidally in five equal modules, with each module consisting of two flip-symmetric half modules. One half module includes five differently shaped NPCs and two PLCs. Each NPC and PLC is fastened to the CSS by two central support elements (CSE). The CSE is a bolted connection allowing possible opening of the flange. The narrow support elements (NSE, 29 per half module) and the lateral support elements (LSE) connect adjacent NPC casings on the high field and on the low field sides of the machine, respectively. The NSEs are sliding contacts, whereas LSEs are welded connections with the exception of the intermodule ones which are bolted. The planar support elements (PSE) connect the two types of PLC (A, B) to the NPC. One PSE per coil (PSE-A1, PSE-B1) is a fixed bolted connection, while other PSEs follow the NSE design [3].

The cryostat system consists of the plasma vessel, outer vessel (OV), the ports and, the machine base. The PV corresponds to the twisted shape of the plasma and is manufactured from 17 $\mathrm{mm}$ thick stainless steel (SS) segments. 254 ports with different shapes (round, oval, rectangular) connect the PV to the 25 $\mathrm{mm}$ thick SS OV. The magnet system is located between 


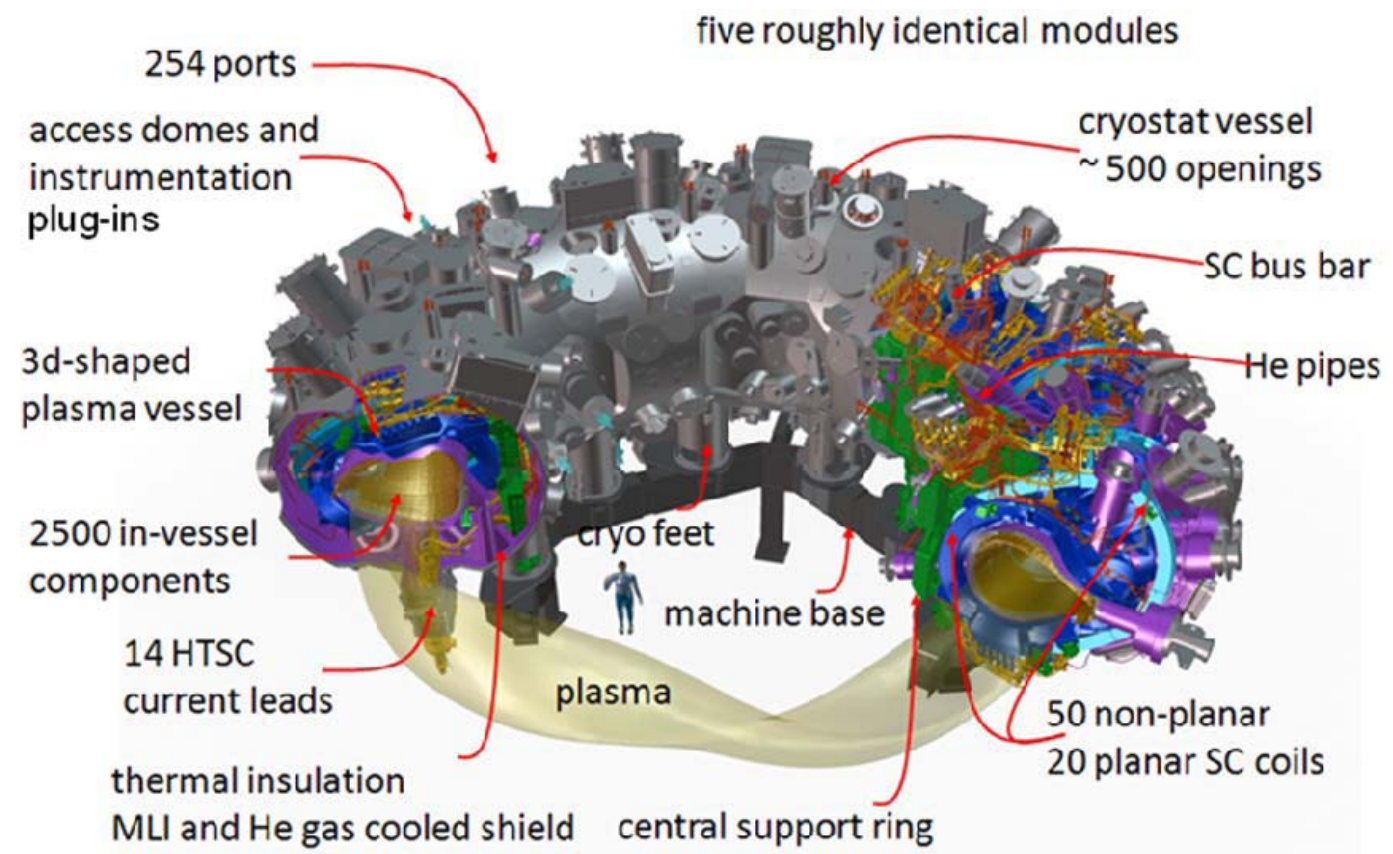

Fig. 2. Schematic diagram of the W7-X stellarator.

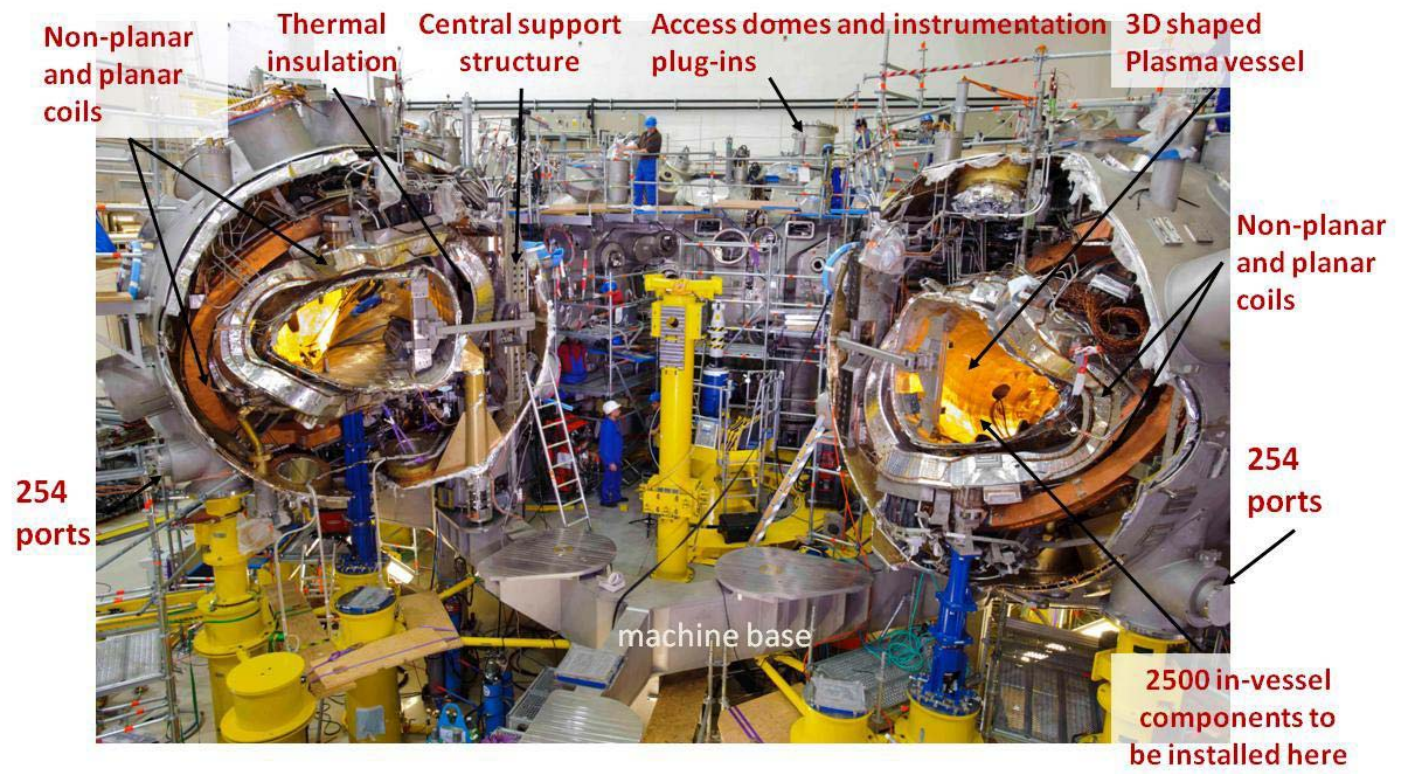

Fig. 3. W7-X assembly status in the end of 2010 with identification of main visible components.

the PV and the OV, and kept at cryogenic temperature $\left(4^{\circ} \mathrm{K}\right) \quad$ II. SPECIFIC FEATURES OF Structural ANALYSES in high vacuum $\left(\sim 10^{-4} \mathrm{~Pa}\right)$.

Plasma facing components (PFCs) such as the divertor,

\section{A. Numerical Modeling in W7-X}

targets baffles, heat shields, and wall panels are being installed Construction of unique fusion devices like W7-X is not in the PV to protect it and other in-vessel components. The possible without intensive numerical modeling. Starting from different PFCs will be exposed to different magnitudes of heat the computational plasma physics to define plasma and magnet loads in the range $0.1-10 \mathrm{MW} / \mathrm{m} 2$ during plasma operation field configurations, itcontinues with the design of vessels and [4], [5]. coils, in-vessel components, auxiliary systems, and diagnos-

Reliable design, construction, and prediction of the W7-X tics. Engineering support with considerable analyses efforts to behavior are only possible with detail numerical modeling. find a compromise between wishes, requirements, structural 


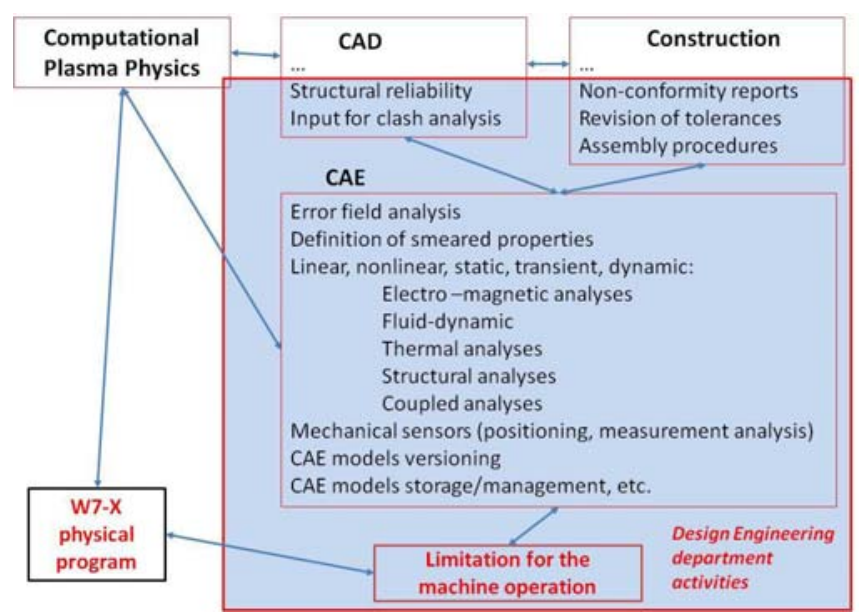

Fig. 4. Numerical modeling: scope of main engineering tasks.

reliability, safety, and cost reduction is a key issue of the design and construction process. It ends up in the definition of limitations for the machine operation and influences the physics program for the device (see Fig. 4). This paper touches several issues of the engineering support process; more detailed information can be found in [3]-[18].

\section{B. Modeling Approaches and Methods}

After the second restructuring of the project in 2004, it was decided to concentrate analyses resources in one department. Activity of the department was started with the development of a clear and transparent strategy [10] based on creation of the tree-shaped numerical model hierarchy with interchange of boundary conditions. The numerical engineering modeling and analyses have then been significantly intensified with considerable external support (see Fig. 10). At that time the main focus was on creation of proper global models (GM) for magnet and cryostat systems, their benchmarking, identification and analysis of critical components using local models, and searching for possible design solutions to reinforce the structures where it was absolutely necessary. Because of limited resources an iterative process was adopted: starting from rough, simplified, conservative models with coarse input and step-by-step refinement in case of criticality until the stress, strain, and deflection/deformation criteria accepted in the project (see Section VI) were met or redesign was clearly necessary.

An example of the evolution of a critical coil support up to the refined local model embedded in the global magnet system model is presented in Fig. 5. The mentioned analysis approach is the most accurate but time consuming, and was implemented only for few of the most critical components.

Two additional GMs have been created and analyzed for MS auxiliary systems: (1) the cryopipe system (see Fig. 6 [11]) and the bus-bar system [14]. Both GMs represent complex mechanical structures that include relatively long and flexible lines together with numerous supports which are mounted on the coils, the CSS, and other components. The supports for both systems are nonlinear due to intentionally introduced

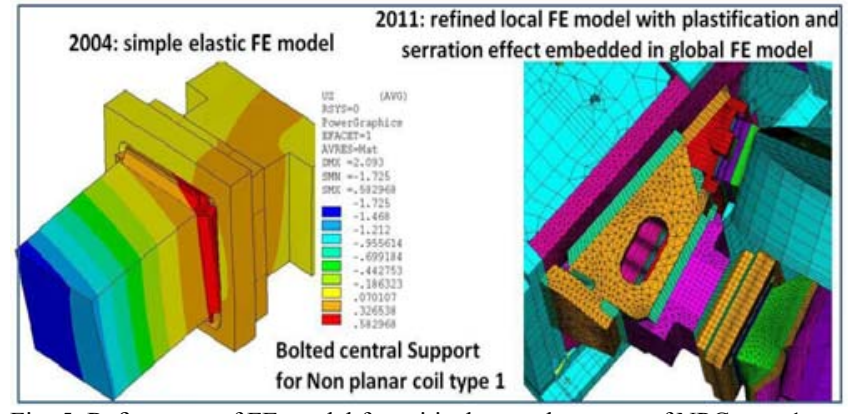

Fig. 5. Refinement of FE model for critical central support of NPC type 1.

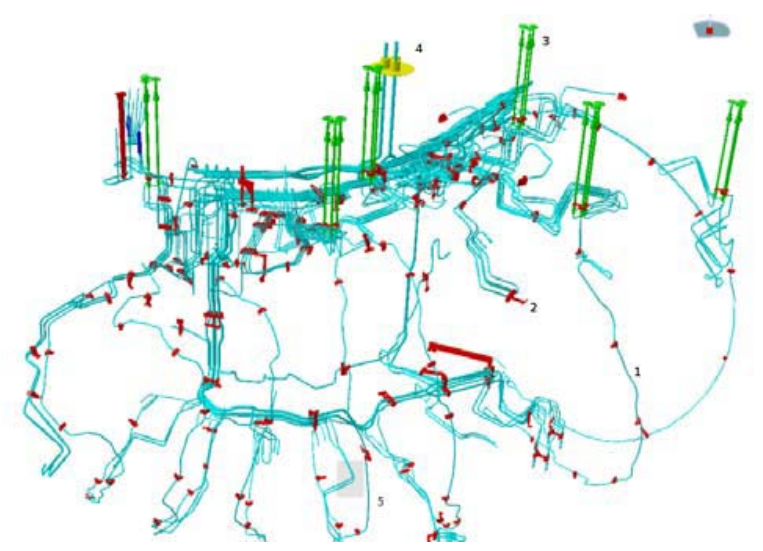

Fig. 6. Global model of helium cryopipe module 5 in ANSYS.

gaps, and the cryopipe system includes numerous flexible hoses and bellows in addition.

\section{Type of Analyses, Elements, and Solvers}

The number and variety of tasks to be solved required drawing together most FE analyses types with suitable elements using appropriate solvers (direct and iterative, implicit, and explicit ones). Static, transient, buckling, and dynamic tasks have to be performed, by considering elastic, elasto-plastic, and/or special rheological models for serration effects and considering temperature-dependent material properties and geometry nonlinearity [13]-[18].

Stress intensity factor analysis and crack propagation considerations require special software utilizing boundary element methods, whereas error field analyses involve Monte-Carlo and line-tracing methods [26].

Standard approaches to simplify and accelerate numerical modeling and analyses have been widely used:

submodeling and superelements, properties homogenizations, beam and shell elements, bonded contact elements to connect dissimilar meshes, etc. Some of sophisticated models with beam, shell and 3-D solid elements are shown in Figs. 6-8.

Hand estimations and special procedure developments for pre-and postprocessor, specific numerical tasks with the help of MatCAD, MATLAB, and MS Excel are the daily life of DE department specialist. 


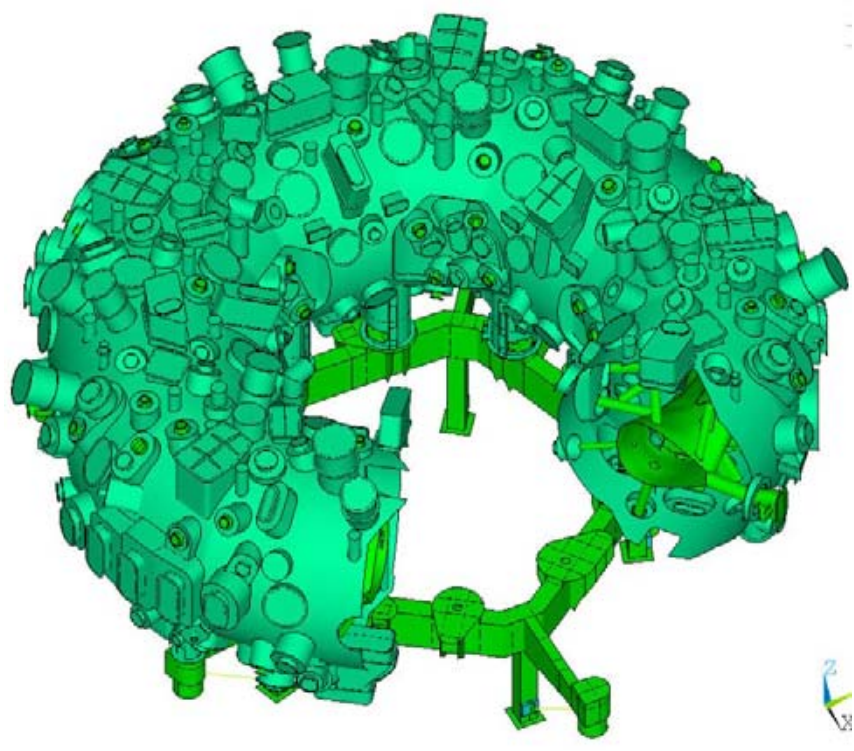

Fig. 7. Updated GM of cryostat system in ANSYS (2013). Shell, beam, and contact elements as well as superelements were used to represent bellows.

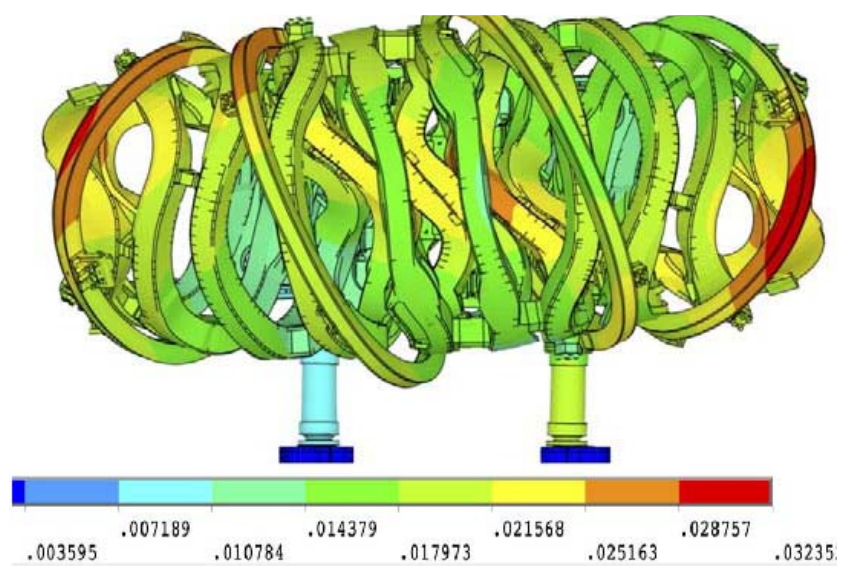

Fig. 8. Magnet system global model (3-D solid model, smeared properties for winding pack, contact, beam, and shell elements). Deflection (m) during operation at high Iota plasma regime in case of maximum "+" tolerances for sliding support gaps between NPC of type 1 .

\section{Software and Packages for Pre-, Post-, and Solution Processors}

One of the most important issues is the choice of proper software tools. It influences both the efficiency of the numerical modeling process as well as the quality and availability of external support. However, it is also important to consider personal experiences in the domestic team especially in tough circumstances when production of main components is ongoing and intensive engineering support is required daily. As a result, the following software was intensively used for the numerical modeling and engineering support:

1) thermal and structural analyses: CATIA/ANSYS, CATIA/ABAQUS, SolidWorks/ANSYS;

2) thermal-hydraulic analysis: Flowmaster, ANSYS Fluent, $\mathrm{CFD} / \mathrm{CFX}$;

3) electromagnetic analyses (EM): EFFI, ELMA*, Maxwell 3-D;
4) crack analyses: + BEASY, ABAQUS;

5) error field analyses: Gordon, ModiCoil*, Opt_Adjust*;

6) estimations/visualization: MATLAB, MatCad.

(* indicate internal IPP development) As a recent example it is worth to mention some complications with preparation of the PV geometry for EM analyses in Maxwell 3-D. It was found that accuracies generally accepted and produced by CAD systems are far outside the limits required in powerful EM package.

\section{LESSONS LEARNED}

Relatively long but successful development and construction of W7-X emphasize well-known items, and highlight new issues in management, design, assembly, manufacturing, and structural analyses [18]-[22]. Five lessons which are most critical for engineering numerical modeling have been formulated and published [18]:

1) a strong and experienced team;

2) benchmark of complex FE models;

3 ) tests of materials and critical components;

4) parameterization of FE models;

5) safety margins and prediction of tolerances.

The first lesson is considered as the most important one and discussed in more detail in Section V.

\section{BENCHMARKING AND VERIFICATIONS}

$\mathrm{W} 7-\mathrm{X}$ is a unique fusion device without practical experience to support reliable confirmation of numerical modeling results. Three main approaches for benchmarking main numerical models and results have been intensely used in the project:

1) benchmarking with independent persons and/or teams;

2) benchmarking with independent models and/or CAE codes;

3) benchmarking with test and assembly results.

\section{A. Benchmarking With Independent Persons and/or Teams}

In most of the cases, the benchmarking with independent person and/or teams was accompanied with alternative numerical models as described in Section III. However, the cryostat system GM (CSGM) was mainly created and modified by the DE team. Nevertheless, each version of the CSGM was created and followed up by a new person with intense benchmarking to fully understand the evolution of obtained results. In addition, numerical models created within the frame of external contracts were checked in detail by DE specialists, rerun, and reused.

\section{B. Benchmarking Between Numerical Models}

Complex FE models similar to the global model of the magnet system (Figs. 8 and 11) are to be benchmarked with independent alternative models of the same complexity. The GM is always a compromise between reasonable representation of main features of the subsystems, computational time, and simplicity for debugging. Therefore, studies of model reliability and sensitivity as well as benchmarking processes are extremely important. During benchmarking among three 
independent global FE models of the magnet system, more than 30 errors have been found and fixed concerning parameters, boundary conditions, and postprocessing routines. The benchmarking process was implemented in parallel with the production and construction process. Inaccuracies which were found required immediate modifications of the structure including reinforcement of welds, introduction of additional ribs and pins, cut and reweld of critical supports, and other corrections. The process was a challenging task owing to existing interfaces with already manufactured coils and components, and space restrictions.

\section{Benchmarking With Component Tests and During Assembly}

Numerical modeling has to be complemented by tests of materials and full, partial, or scaled prototypes for highly loaded structural elements.

Worth to mention test programs supported by intensive structural analysis for highly loaded NSEs, CSEs, cryolegs, and conductor connections [23], as well as for the mechanical quench test on the superconducting NPC type 2 under current [24], [25]. Quality assurance for incoming material is also very important. The requirements for structural material properties are high, and variations are usually not acceptable. The test program for the magnet system was successfully completed with the tests of EKagrip friction enhancing foils for the elements to be installed at the module separation interfaces. Important issues concerning the design of PFCs and diagnostics are thermomechanical analyses to verify their suitability for the specified operation phases. A series of finite element (FE) simulations has been performed to achieve this goal with intense benchmarking against various tests (see list of references in [18]).

\section{Safety Factors on Forces/Moments and Displacements}

The global and local FE models allow prediction of the structural behavior with some accuracy only because of several well-recognized assumptions and simplifications in FE model as well as incomplete load input information from component users. As a consequence, the choice of safety margins to be applied on "pure" FE analyses results has to be properly made. For the forces and moments extracted from GMs and used in the local analysis and/or design of subcomponents, the factor of 1.2 has been generally assumed for normal operation conditions. The factor is reduced for unlikely and very unlikely regimes down to 1.1. and 1.0, respectively, to reflect the fact that the probability of such events is, respectively, lower and the supporting system for main subcomponents is, to some extent, redundant.

The safety margin for calculated FE displacements is accepted as a factor of 1.5 , but with completely different reasoning.

The driving factor for the magnet system is a limitation of resources for complex and highly time consuming clash analyses. To save resources in back office department, the results for only four plasma configuration regimes have been chosen and used for the collision check after application of mentioned above safety margin.
The main uncertainties in the displacement of cryostat system components are:

1) weld residual stresses which are not relieved in the system by special procedures;

2) CS deformation/internal residual stresses after reposition from temporary to permanent supports;

3) measurement accuracy for the determination of PV and/or OV position;

4) influence of not fully penetrated welds on the component stiffness and displacements;

5) inaccuracy of centering/adjustment procedure for the PV;

6) discretization and interpolation peculiar to FE method;

7) inaccuracy in input definition (geometry and diagnostic weight/load approximations);

8) variation of material properties (Young modules, Poisson ratio, thermal expansion coefficient, etc.);

9) tolerances of plate thicknesses (e.g., the main OV shell

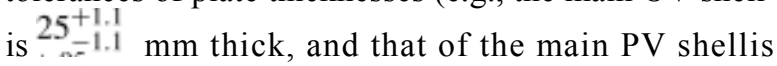
$17_{-.95}^{+.95}$ and weld tolerances;

10) difficulties in predicting thermal gradients in the cryostat shells.

Moreover, it was well understood that the cryostat global model is a linear elastic FE model and in spite of the fact that the probability of unlikely, very unlikely, and extremely unlikely events reduces drastically from one to another, the damage limits accepted for components are local, large, and gross deformations, respectively. As a result, yielding which is accepted in these cases is far beyond the linear elastic predictions. Therefore, a uniform 1.5 factor is applied on the GMCS displacements for all load cases to produce an input for the diagnostics and other related components.

\section{DOMESTIC TEAM AND EXTERnAl SuPPORTS}

Unique devices like W7-X, ITER, CFETR, and other large fusion experiments require strong and experienced domestic teams for numerical modeling from the beginning of the project. The team should grow gradually in size and experience toward construction of the device. An example shall demonstrate what might happen if the staffing is not sufficient: the W7-X planar coil case is a bolted and pinned structure. Because of lack of resources until 2005, as shown in Fig. 10, modeling and analysis of the case was originally performed only as solid body, and this was judged as good enough. As a result, the deformation of the coil was considerably underestimated. In addition, the detailed analysis showed complete breakage of the fasteners and overloading of the winding pack. The correction measures which had to be applied to already manufactured coils included drilling and installation of 300-400 additional pins in the coil cases, and change of the planar support elements [18].

Most of the local analyses usually have been carried out in collaboration with subcontractors in the framework of national and international contracts. The W7-X experience demonstrates again that such outsourcing is to be made very carefully to ensure created FE models can be reused. Therefore, all external contracts are to be closely followed by 
advanced specialists of the project team. Complex analysis of components with nonlinear behavior is prone to errors and has to be carefully checked and rerun by the team.

\section{STRUCTURAL CODES FOR W7-X}

The state-of-the-art fusion devices are always beyond developed and accepted criteria. The choice of codes and standards (C\&S) for W7-X stellarator follows the same multicode approach as accepted by ITER [31]. However, W7-X is a low cycle experimental machine. Therefore, structural criteria developed for tokamaks such as ITER were correspondingly expanded or relaxed on the basis of tests and experience to achieve reasonable cost reduction as listed below [29]. In general, the W7-X structural design criteria for the cryogenic magnet system follow the ones developed for ITER in 2004. However, criteria for critical components, welds, handmade insulation, and other unique elements were extended and elaborated on the basis of extensive test programs and FE limit analyses by also considering the material serration effects [14]-[17].

1) Magnets System:

Acceptance of plastification based on FE estimation of serration effects in components.

Acceptance of cracks based on analysis.

Acceptance of local delamination of turn insulation.

Tests of all critical components and benchmarking with FE analysis. Acceptance of improbable stick-slip effects based on test results (MQ test [24], [25]).

2) Cryostat System:

Nonstandard welds: relatively high weld efficiency factors are assumed even for welds where inspection was limited.

3) Cryopipe System:

Acceptance of cold material properties as basis for allowable stress values (not room temperature ones as in other structural codes).

4) In-Vessel Components:

Acceptance by tests.

\section{FURTHER ACTIVITIES}

\section{A. $W 7-X$}

Currently, the focus of activities is shifted to in-vessel components, diagnostics and periphery [18], [30], as well as to fast analyses of nonconformities (NCR) reported by manufacturers and the assembly team. Error field analyses are to be completed to specify the initial current configuration of the trim coils [26]-[29]. Last assembly steps which include reposition of the PV from temporary sliding tables to permanent pendulum supports and removal of temporary supports underneath machine base cantilevers require special attention of the department to avoid any disturbances of already achieved accuracy.

Another huge bundle of the work is the preparation for commissioning and the first phase of operation in terms of handbook creation for the interpretation of signals from mechanical and temperature sensors. Limitations, if any, for

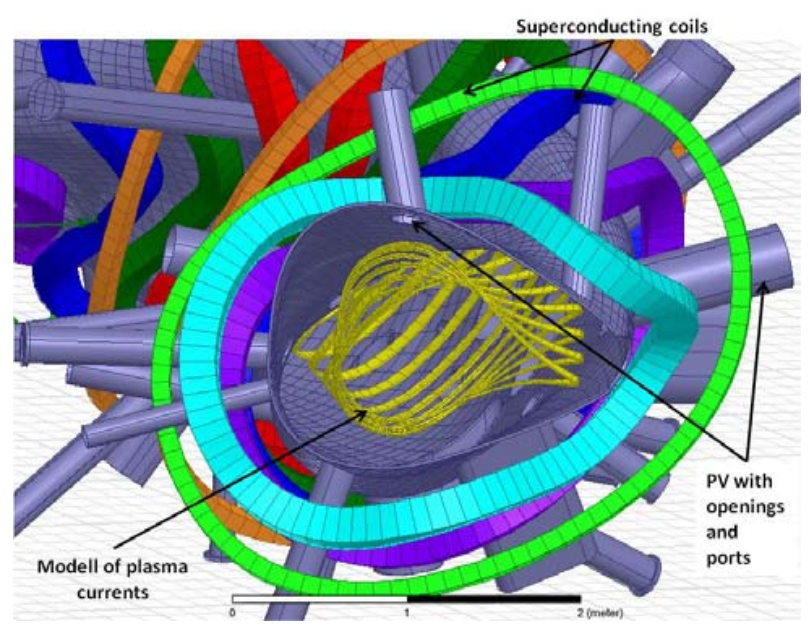

Fig. 9. Cross section of global electromagnetic model (MAXWELL 3-D).

initial magnet system energizing tests and startup of OP1, have to be defined in the nearest future. With the start of commissioning it is necessary to collect and interpret sensor information for verification and adjustment of the FE models and predictions.

During the initial short pulse campaigns (OP1.1/OP1.2) there is a need to continue the support of diagnostic design for long plasma operation (OP2) with more accurate numerical models (see Fig. 9 [12]), as well as the design and assembly of components to build in-between OP1 and OP2 such as port liners, high heat flux divertor, heating systems, etc.

The department resources are also being allocated for the creation of 3-D FE models for all representative in-vessel component modules to accurately estimate gaps and leading edge problems on the basis of surface temperature measurements.

\section{B. Stellarator DEMO}

The fusion experiment $\mathrm{W} 7-\mathrm{X}$ shall demonstrate the reactor potential of a HELIAS-type stellarator. HELIAS reactors (HSR) with three, four, and five periods have been studied at IPP for many years. Assuming a plasma axis induction of around $5 \mathrm{~T}$, corresponding to about $10 \mathrm{~T}$ maximal induction at the coil conductors, it was shown that such reactors are feasible. Considering recent developments in superconductor technology, and in particular considering the extensive technical development work performed so far for ITER, the possibility is being investigated to increase the conductor induction up to the $12 \mathrm{~T}$ range corresponding to a plasma axis value $>5.5 \mathrm{~T}$. This improves the stellarator confinement properties but would not change the basic physics with respect to the previously analyzed machines. For this study, the five periodic HELIAS type, HELIAS 5-B, is taken which basically evolves from W7-X by linear scaling of the main dimensions by about a factor of four. By coincidence the coil circumference lengths of HSR5 are almost exactly the same as those of the ITER toroidal field coils.

For this $>12 \mathrm{~T}$ reactor version also, the conductor and structural requirements are comparable with the corresponding 


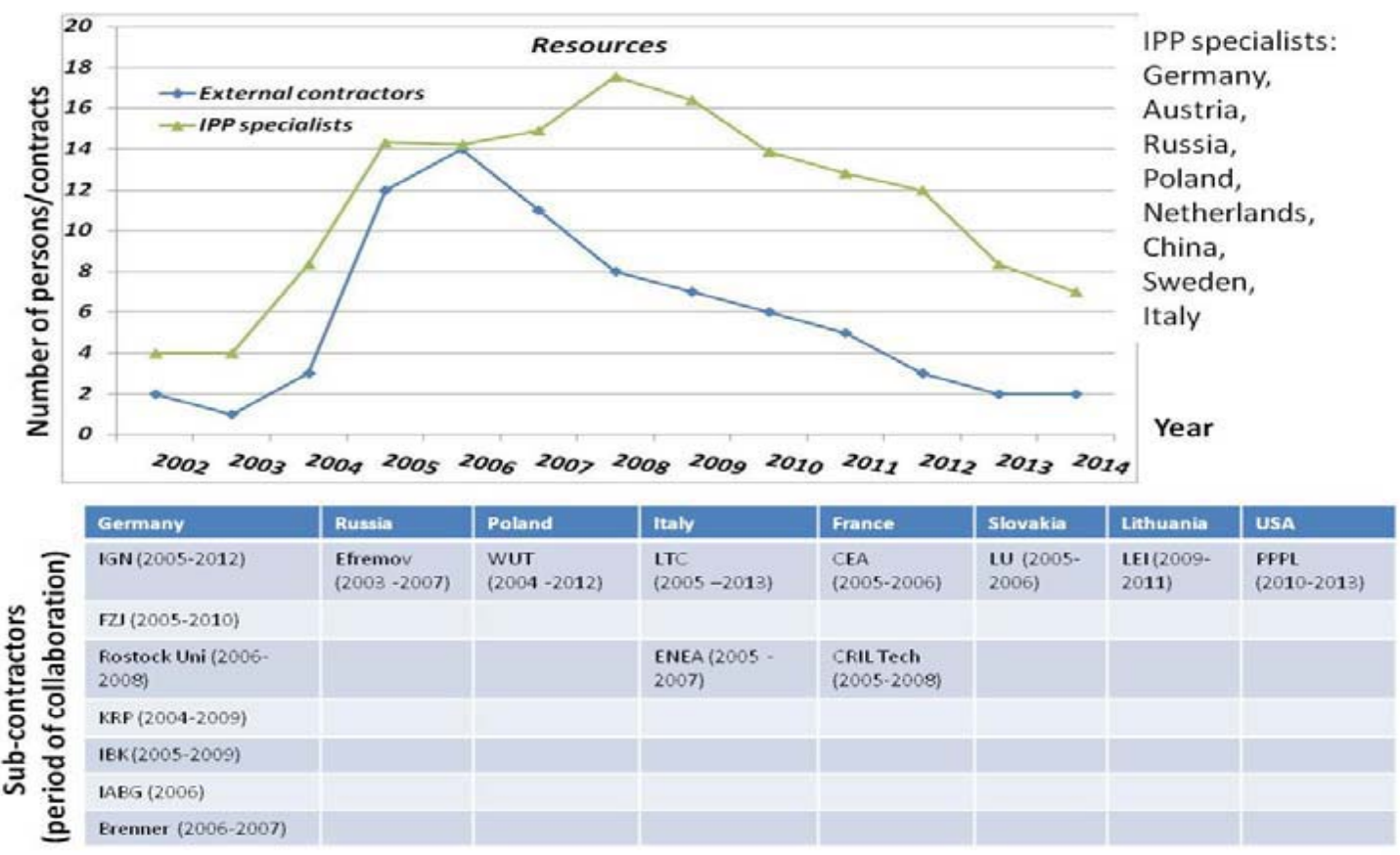

Fig. 10. Resource allocation and external support for CAE activity (mainly in W7-X DE department) during 2002-2014.

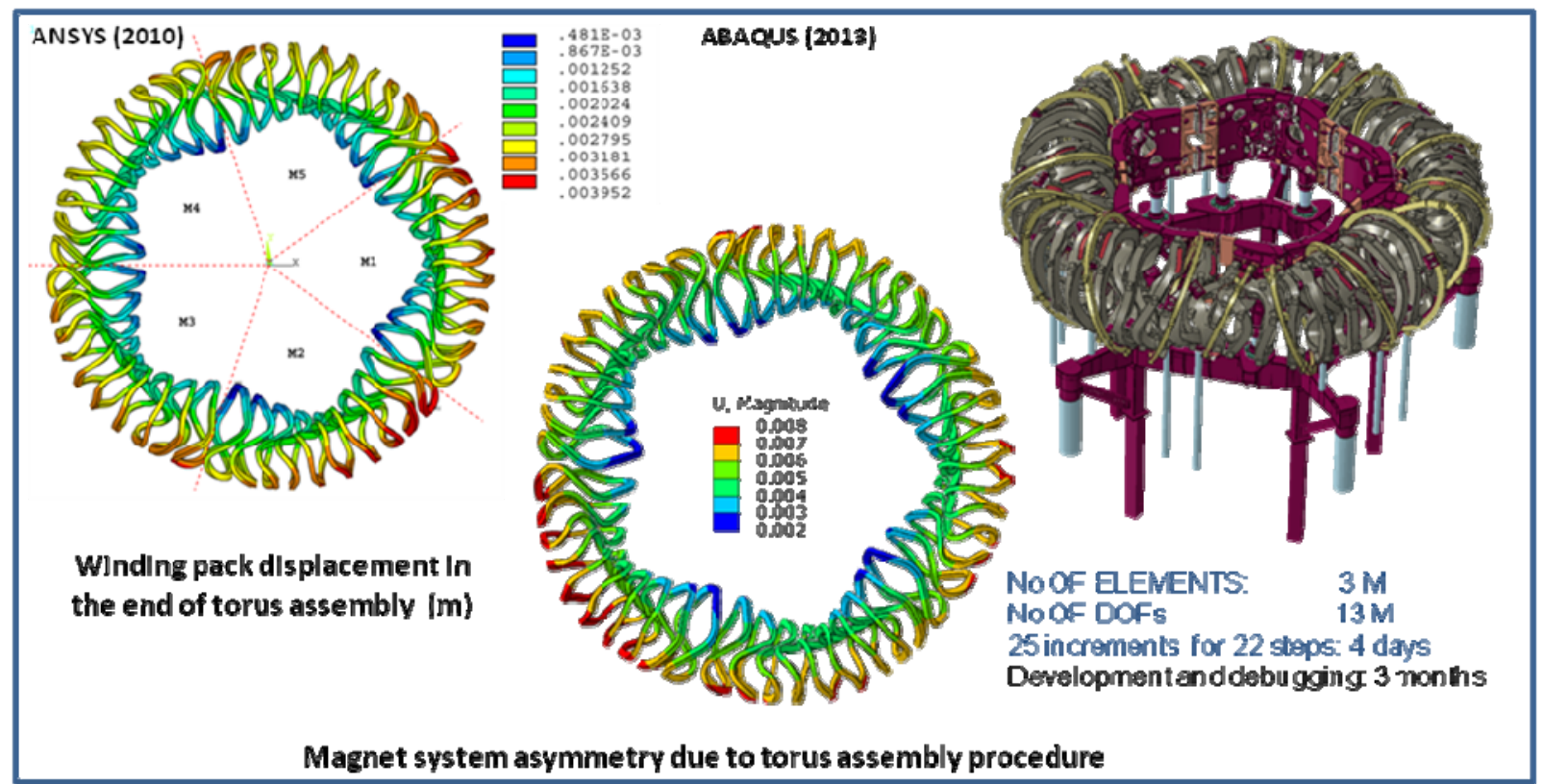

Fig. 11. Estimation of magnet system asymmetry as a result of torus assembly. Displacements (m) in ANSYS and ABAQUS $360^{\circ}$ global models.

ITER specifications. Therefore, advantage is taken of these similarities, and the conceptual magnet design is based wherever applicable on ITER solutions.

Within the frame of this study, supported by EURATOM, it is shown that such a HELIAS stellarator magnet system is feasible. $\mathrm{Nb}_{3} \mathrm{Sn}$ conductor with the same current density as in ITER would be sufficient.

Mechanical support between the coils is provided by a building block structure whose elements can be series-produced and easily assembled. The optimization process of this structure is ongoing. In addition, a scaling of the created HELIAS 5B version to a smaller stellarator machine is considered on the basis of corresponding fusion energy scaling law to fulfill requirements of the Horizon 2020 European program in the development of intermediate experimental stellarator [32]. Activities are underway with Euratom support for further physics and engineering developments.

\section{CONCLUSION}

The following conclusions can be drawn from the work of the W7-X design engineering.

1) Structural analysis strategies were developed and implemented.

2) FE model trees were created, reused, and are basically ready for the operation phases. 
[1] T. Klinger, "Wendelstein 7-X construction and future research directions," in Proc. IEEE 25th Symp. Fusion Eng., Jun. 2013, no. ThPL-3, pp.

3) The construction of W7-X is on track and machine commissioning to be started in the Spring of 2014 is underway from the numerical modeling point of view.

4) The lessons learned were summarized and published.

5) Experiences concerning structural development and analysis are being successfully used for the engineering development of a stellarator reactor.

Technical challenges are still ahead, but the team is confident to successfully face and resolve them, to achieve the major W7-X goals, and to continue research and development towards a HELIAS type reactor.

\section{ACKNOWLEDGMENT}

The authors would like to thank all collaborators for long and reliable work on W7-X analyses with special thanks to LTC, Italy, WUT, Poland, IGN, Germany, Efremov Institute, Russia and FZJ, Germany.

\section{REFERENCES}

$$
1-4
$$

[2] H.-S. Bosch, R. Brakel, M. Gasparaotto, R. Herrmann, D. Hartmann, and D. Naujoks, "Preparation of the Wendelstein 7-X commissioning," in Proc. IEEE 25th Symp. Fusion Eng., Jun. 2013, no. TO1-5, pp. 1-4.

[3] P. van Eeten, D. Hathiramani, V. Bykov, A. Cardella, A. Dudek, J. Holluba, et al., "Design and test of the support element of the W7-X superconducting magnets," in Proc. IEEE 22nd Symp. Fusion Eng., Jun. 2007, pp. 1-4.

[4] A. T. Peacock, J. Boscary, H. Greuner, P. Junghanns, B. Mendelevitch, M. Smirnow, et al., "Wendelstein 7-X high heat flux components," in Proc. IEEE 25th Symp. Fusion Eng., Jun. 2013, no. ThO2-1, pp. 1-4.

[5] J. Tretter, J. Boscary, B. Mendelevitch, A. Peacock, and R. Stadler, "Configuration space control of in-vessel components for Wendelstein 7X," in Proc. IEEE 25th Symp. Fusion Eng., Jun. 2013, no. TPO-128, pp. $1-6$.

[6] A. Tereshchenko, V. Bykov, F. Schauer, M. Y. Ye, S. Weißflog, and T. Andreeva, "FE simulation of the Wendelstein 7-X cryostat system," Fusion Eng. Des., vol. 84, nos. 7-11, pp. 1833-1837, Jun. 2009.

[7] V. Bykov, F. Schauer, K. Egorov, A. Tereshchenko, P. van Eeten, A. Dübner, et al., "Structural analysis of W7-X: Overview," Fusion Eng. Des., vol. 84, nos. 2-6, pp. 215-219, Jun. 2009.

[8] V. Bykov, F. Schauer, K. Egorov, P. van Eeten, C. Damiani, A. Dübner, et al., "Structural analysis of W7-X: Main results and critical issues," Fusion Eng. Des., vol. 82, nos. 5-14, pp. 1538-1548, Oct. 2007.

[9] V. Bykov, F. Schauer, P. van Eeten, K. Egorov, A. Tereshchenko, A. Dubner, et al., "Main results and critical issues of W7-X structural analysis," in Proc. IEEE 22nd Symp. Fusion Eng., Jun. 2007, pp. 1-4.

[10] V. Bykov, M. Gasparotto, N. Jaksic, K. Egorov, M. Sochor, L. Sonnerup, et al., "Strategy of structural analysis of W7-X magnet system," in Proc. 21st IEEE/NPS Symp. Fusion. Eng., 2006, no. 04_11, pp. 1-4.

[11] A. Dübner, D. Zacharias, M. Nagel, V. Bykov, F. Schauer, and M. Ihrke, "Structural analysis of the W7-X cryogenic pipe system," Fusion Eng. Des., vol. 84, nos. 2-6, pp. 694-697, Jun. 2009.

[12] M. Köppen, V. Bykov, and F. Schauer, "Detailed analysis of eddy currents in wendelstein 7-X," in Proc. 28th Symp. Fusion Technol., 2014, to be published.

[13] K. Egorov, V. Bykov, F. Schauer, and P. van Eeten, "Structural analysis of Wendelstein 7-X magnet weight supports," Fusion Eng. Des., vol. 84, no. 2, pp. 722-728, Jan. 2009.

[14] O. Neubauer, A. Panin, B. Giesen, and G. Czymek, "Approaches to numerical modeling in development process of complex structures for fusion devices," in Proc. IEEE 25th Symp. Fusion Eng., Jun. 2013, no. WO3-2, pp. 1-8.

[15] J. Fellinger, V. Bykov, and F. Schauer, "Serrated yielding at cryogenic temperatures in structural components of wendelstein 7-X," Appl. Supercond., vol. 22, no. 3, p. 4801504, 2012.

[16] Ł. Ciupi'nski, G. Krzesi'nski, P. Marek, T. Zagrajek, J. Fellinger,
V. Bykov, et al., "Limit analysis of W7-X critical magnet system components with consideration of material serration effect," Fusion Eng. Des., vol. 86, nos. 6-8, pp. 1501-1505, Oct. 2011.

[17] E. Briani, C. Gianini, F. Lucca, A. Marin, J. Fellinger, and V. Bykov, "Limit analysis of narrow support elements in W7-X considering the serration effect of the stress-strain relation at 4K," Fusion Eng. Des., vol. 86, nos. 6-8, pp. 1462-1465, Oct. 2011.

[18] V. Bykov, F. Schauer, K. Egorov, P. van Eeten, J. Fellinger, M. Sochor, et al., "Structural analysis of W7-X: From design to assembly and operation," Fusion Eng. Des., vol. 86, nos. 6-8, pp. 645-650, Oct. 2011.

[19] T. Klinger, C. Baylard, C. D. Beidler, J. Boscary, H. S. Bosch,

A. Dinklage, et al., "Towards assembly completion and preparation of experimental campaigns of Wendelstein $7-\mathrm{X}$ in the perspective of a path to a stellarator fusion power plant," Fusion Eng. Des., vol. 88, nos. 6-8, pp. 461-465, Oct. 2013.

[20] R. Vilbrandt, H. -S. Bosch, J. -H. Feist, "Do we need a quality management system in fusion esearch? - Experience from W7-X", in Proc. IEEE 25th Symp. Fusion Eng., Jun. 2013, no. TPO-129, pp. 1-4.

[21] C. Baylard, D. Hartmann, S. Renard, M. Banduch, D. Beiersdorf, T. Kobarg, et al., "Concurrent engineering and mechanical integration in the experimental hall of wendelstein 7-X: Issue, solutions, lessons learned," in Proc. IEEE 25th Symp. Fusion Eng., Jun. 2013, no. ThO6-3, pp. $1-4$.

[22] K. Rummel, A. John, and L. Hajduk, "Experiences from the installation of the superconducting bus bar system of Wendelstein 7-X," in Proc. IEEE 25th Symp. Fusion Eng., Jun. 2013, no. TPO-64, pp. 1-5.

[23] T. Rummel, T. Moennich, K.-P. Buscher, F. Schauer, W. H. Fietz, and R. Heller, "The current leads of the Wendelstein 7-X superconducting magnet system," in Proc. IEEE 25th Symp. Fusion Eng., Jun. 2013, no. TO2-4, pp. 1-6.

[24] D. Hathiramani, T. Bergmann, V. Bykov, P. Chen, W. Danner, A. Dudek, et al., "Stability test of a superconducting W7-X coil with respect to mechanical disturbances," IEEE Trans. Appl. Supercond., vol. 20, no. 3, pp. 543-546, Jun. 2010.

[25] J. Fellinger, S. Freundt, D. Hathiramani, V. Bykov, and F. Schauer, "Dynamic response analysis of superconducting coils in Wendelstein 7-X, and mechanical quench test," Fusion Eng. Des., vol. 86, nos. 6-8, pp. 1385-1388, Oct. 2011.

[26] T. Andreeva, V. Bykov, K. Egorov, M. Endler, J. Fellinger, J. Kißlinger, et al., "Influence of assembly and operation asymmetries on Wendelstein 7-X magnetic field perturbations," in Proc. 40th EPS Conf. Plasma Phys., P2.106, 2013, pp. 1-4

[27] J. Fellinger, K. Egorov, J. P. Kallmeyer, V. Bykov, and F. Schauer, "Asymmetry of Wendelstein 7-X magnet system introduced by torus assembly," Fusion Eng. Des., pp. 1-4, 2014, to be published .

[28] K. Risse, S. Freundt, F. Fuellenbach, M. Koeppen, T. Rummel, R. Hatcher, et al., "Wendelstein 7-X trim coils-Component safety aspects and commissioning strategy," in Proc. IEEE 25th Symp. Fusion Eng., Jun. 2013, no. TPO-72, pp. 1-4.

[29] V. Bykov, J. Fellinger, and F. Schauer, "Structural criteria for W7-X," Max Planck Inst. Plasma Phys., Greifswald, Germany, Tech. Rep. 1GXS0004, 2005.

[30] X. B. Peng, V. Bykov, M. Köppen, M. Y. Ye, J. Fellinger, A. Peacock, et al., "Thermo-mechanical analysis of Wendelstein 7-X plasma facing components," Fusion Eng. Des., vol. 88, nos. 9-10, pp. 1727-1730, Oct. 2013.

[31] V. Barabash, G. Sannazzaro, N. Mitchell, C. Jong, B. Giraud, K. Ioki, et al., "Codes and standards and reulation issues for design and construction of the ITER mechanical components," Fusion Eng. Des., vol. 85, nos. 79, pp. 1290-1295, Dec. 2010.

[32] F. Romanelli, "A roadmap to the realization of fusion energy," in Proc. IEEE 25th Symp. Fusion Eng., Jun. 2013, no. TPL-3, pp. 1-4.

Authors' photographs and biographies not available at the time of publication 
